\title{
EROSIVE EFFECT OF ASPIRIN ON PRIMARY TEETH ENAMEL IN CHILDREN WITH HEART DISEASE (AN IN VIVO STUDY)
}

\author{
Brdis S. Abdelaziz*, Amr M. Abdel Aziz* , Gehan G. Ibrahim* and Hala M. Mohammed ${ }^{* * *}$
}

\begin{abstract}
Aim: The purpose of this in vivo study was to Comparing prevalence of dental erosion in different groups of children with heart diseases. Materials and Methods: A total of 51 children from the outpatient's clinic of national heart institute, were included in this study their age ranged from 3-15 years old, children were divided into three groups according to doses of aspirin taken : (A) : children with RHD who take aspirin in high dose for short duration in chewable form $75 \mathrm{mg} / \mathrm{kg} / \mathrm{day}, \mathrm{n}=17 \mathrm{children}$, (B)children with cyanotic heart diseases who take aspirin in low dose for long duration in chewable form $5 \mathrm{mg} / \mathrm{kg} / \mathrm{day}, \mathrm{n}=17 \mathrm{children,} \mathrm{(C)} \mathrm{:chil-}$ dren with acyanotic heart disease who don't take aspirin $n=17$ children. All children were examined intra orally to measure dental erosion by using o`sullivan erosion index. Results: The highest percentage of dental erosion was found in Group (B) followed by Group (A) then Group (C). Conclusion: In this in vivo study aspirin caused dental erosion due to its acidic $\mathrm{pH}=3$ but sever erosion occurred in the group of children who consumed aspirin for long duration
\end{abstract}

\section{INTRODUCTION}

Heart disease is one of the most common developmental abnormalities among children, occurring in approximately 8 to 10 in 1,000 births $^{(1)}$.

Heart diseases observed in children and adolescents are mainly congenital heart disease and acquired heart disease ${ }^{(1)}$.

Many studies showed that, children with heart disease have higher enamel hypoplasia and caries prevalence than normal children, and that could be due to many reasons such as their attitude and knowledge toward oral hygiene measures, sugary diet and medications that could increase their susceptibility to caries and acidic drugs that cause erosion ${ }^{(2)}$.

In children, dental erosion become a major problem in past years, recent studies showed that the prevalence of dental erosion is increasing ${ }^{(3)}$.

Studies have reported prevalence rates of dental erosion ranging from $13 \%$ to $75 \%$ among 12 -yearold children ${ }^{(4)}$.

The frequent use of acidic medications such as aspirin which is used as anticoagulant in children with heart diseases and come in direct contact with teeth is identified as an extrinsic etiologic factor in dental erosion, not only for adults but also for children $^{(4-6)}$.

ASPOCID $75 \mathrm{mg}$ chewing tablets is the usual drug used in children with heart disease, these medicines are available in Egyptian markets and accessible by the public. Each tablet of ASPOCID contains $75 \mathrm{mg}$ acetylsalicylic acid and its $\mathrm{pH}=3$.

Children with heart diseases take aspirin in chewable tablets which comes in direct contact with their teeth especially occlusal surfaces and that increase their susceptibility to dental erosion, usual doses are $75-100 \mathrm{mg} / \mathrm{kg} /$ day divided on 4 doses for 2- 6 weeks to treat inflammation in children with rheumatic heart disease (RHD) and $5 \mathrm{mg} / \mathrm{kg} / \mathrm{day}$ in

\footnotetext{
* Professor and head of Pediatric Dentistry and Dental Public Health Department, Faculty of Dentistry Ain Shams University ** Lecturer of Pediatric Dentistry and Dental Public Health, Faculty of Dentistry Ain Shams University

*** Lecturer Department of Pediatrics at National Heart Institute.
} 
single dose daily for life long to act as antiplatelet in children with congenital heart disease (CHD) ${ }^{(2)}$.

This study is conducted to compare the prevalence of dental erosion in different groups of children with heart diseases and to evaluate the effect of chewing aspirin on the micro hardness of primary teeth and comparing it with the effect of soluble form of aspirin.

\section{MATERIALS AND METHODS}

In vivo study was conducted by clinical examination of children aged from 3-15 years from both gender collected from National Heart Institute.

A total number of 51 (17 in each group) is calculated using Epicalc program version 1.02 assuming a power of $80 \%$ and alpha $=0.05$. The sample size is based on percentage of affected tooth surfaces by dental erosion for those reporting dental erosion on (labial or buccal only) and (lingual and incise 1/ occlusal) was $505(30.3 \%)$ and $109(6.6 \%)$, respectively.

Children was divided according to aspirin medication into three groups: First group: children with RHD who take aspirin in high dose for short duration in chewable form $75 \mathrm{mg} / \mathrm{kg} /$ day, $\mathrm{n}=17$ children (figure 1). Second group: children with $\mathrm{CCD}$ who take aspirin in low dose for long duration in chewable form $5 \mathrm{mg} / \mathrm{kg} /$ day, $\mathrm{n}=17$ children. Third group: children with acyanotic heart disease who don't take aspirin $n=17$ children, due to lack of hypoxia and subsequently lack of erythrocytosis there is no need for aspirin or any substitute unlike cyanotic heart disease ${ }^{(7)}$. (figure 2)

For the first two groups aspirin was taken in chewable form, for at least 3 weeks regarding the first group and more than 6 months for second group.

Collected children were examined at national heart institute's dental clinic Children clinically ex- amined under standard artificial illumination using plane mouth mirrors, gloves, and sterilized gauze to remove gross debris. Dental erosion is measured by using O'Sullivan index, which is especially designed for epidemiological surveys and for diagnosis of erosion in children ${ }^{(8)}$. After examination fluoride varnish was applied to all teeth.

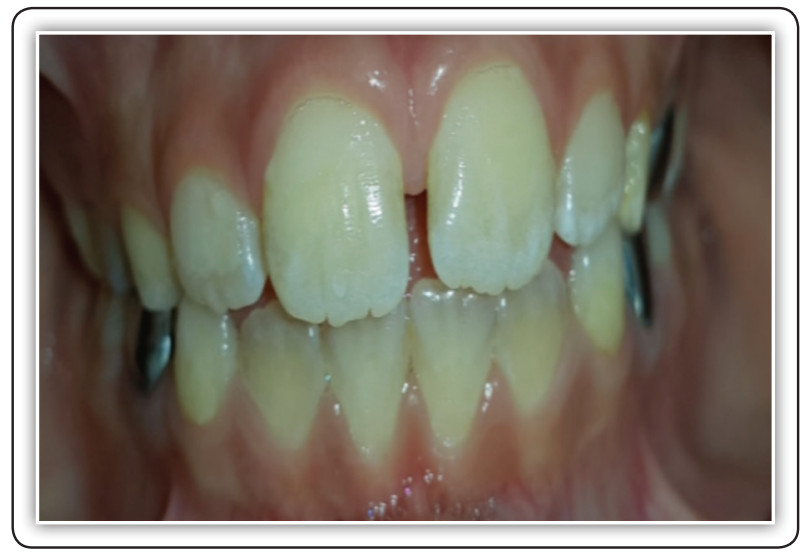

Fig. (1): Child with RHD.

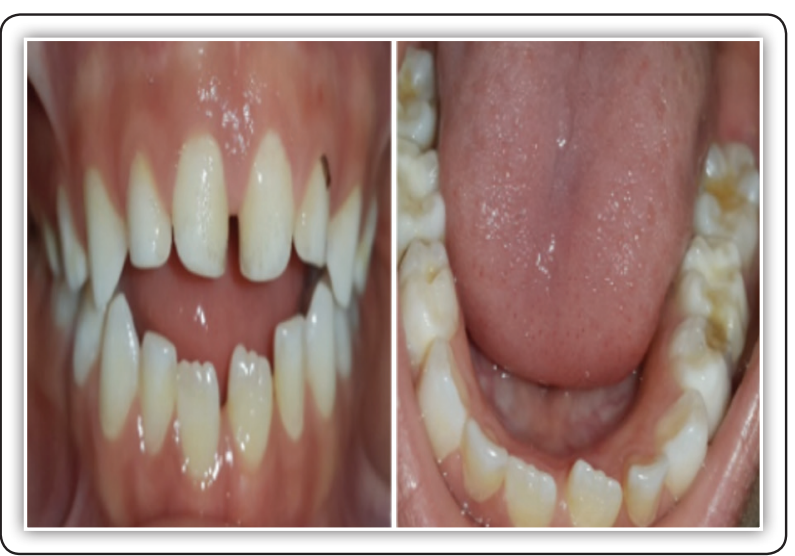

Fig. (2): Child with acyanotic heart disease.

\section{RESULTS}

1- Compariosn of the prevalence of dental erosion in all groups:

Frequencies (n), Percentages (\%), for the prevalence of dental erosion in all groups in table (1) and figure (3) 
TABLE (1): Frequencies (n), Percentages (\%) for prevalence of dental erosion in all groups

\begin{tabular}{|c|c|c|c|c|c|}
\hline \multicolumn{2}{|c|}{ Dental erosion } & Group & Group & $\begin{array}{c}\text { Group } \\
\text { (II) }\end{array}$ & P-value \\
\hline \multirow{2}{*}{ Yes } & $\mathbf{n}$ & 248 & 302 & 227 & \multirow{8}{*}{$<0.001 *$} \\
\hline & $\%$ & $68.9 \%^{\mathrm{A}}$ & $89.1 \%^{\mathrm{B}}$ & $66.4 \%{ }^{\mathrm{A}}$ & \\
\hline \multirow{2}{*}{ No } & n & 79 & 13 & 86 & \\
\hline & $\%$ & $21.9 \%^{\mathrm{A}}$ & $3.8 \%{ }^{\mathrm{B}}$ & $25.1 \% \mathrm{~A}^{\mathrm{A}}$ & \\
\hline \multirow{2}{*}{$\begin{array}{l}\text { Can't be } \\
\text { detected }\end{array}$} & n & 33 & 24 & 29 & \\
\hline & $\%$ & $9.2 \%{ }^{\mathrm{A}}$ & $7.1 \% \mathrm{~A}^{\mathrm{A}}$ & $8.5 \%{ }^{\mathrm{A}}$ & \\
\hline \multirow{2}{*}{ Total } & n & 360 & 339 & 342 & \\
\hline & $\%$ & $100 \%$ & $100 \%$ & $100 \%$ & \\
\hline
\end{tabular}

Different superscript letters within the same row indicates a statistically significant difference *; significant $(p \leq 0.05) n s ;$ non-significant $(p>0.05)$

The highest percentage of dental erosion was found in Group (II) followed by Group (I) then Group (III). The highest percentage of teeth free of dental erosion was found in Group (III) followed by group (I) then Group (II). The highest percentage of teeth that couldn't be detected for erosion was found in Group (III) followed by Group (I) then Group (II). The majority of teeth in all groups had dental erosion. There was a significant difference between the three groups. Pairwise comparison for teeth with and without erosion showed no significant difference between groups (I) and (III), while group (II) was significantly different from both groups. For teeth that can't be detected for erosion pairwise comparison showed no significant difference.

\section{2- Compariosn of the site of dental erosion in all groups}

Frequencies (n), Percentages (\%), for the site of dental erosion in all groups in table (2) and figure (4)
TABLE (2): Frequencies (n), Percentages (\%) for the site of dental erosion in all groups

\begin{tabular}{|c|c|c|c|c|c|}
\hline \multicolumn{2}{|c|}{ Site of erosion } & $\begin{array}{c}\text { Group } \\
\text { (I) }\end{array}$ & $\begin{array}{c}\text { Group } \\
\text { (II) }\end{array}$ & $\begin{array}{c}\text { Group } \\
\text { (III) }\end{array}$ & P-value \\
\hline \multirow{2}{*}{ Code (A) } & $\mathbf{n}$ & 51 & 38 & 52 & \multirow{14}{*}{$<0.001 *$} \\
\hline & $\%$ & $19.8 \%{ }^{\mathrm{AB}}$ & $12.6 \%^{\mathrm{B}}$ & $22.9 \%{ }^{\mathrm{A}}$ & \\
\hline \multirow{2}{*}{ Code (B) } & $\mathbf{n}$ & 11 & 1 & 2 & \\
\hline & $\%$ & $4.3 \%{ }^{\mathrm{A}}$ & $0.3 \%^{\mathrm{B}}$ & $0.9 \% \mathrm{AB}$ & \\
\hline \multirow{2}{*}{ Code $(C)$} & n & 42 & 35 & 54 & \\
\hline & $\%$ & $16.3 \%$ АВ & $11.6 \%{ }^{\mathrm{B}}$ & $23.8 \%{ }^{\mathrm{A}}$ & \\
\hline \multirow{2}{*}{ Code (D) } & n & 67 & 84 & 78 & \\
\hline & $\%$ & $26.1 \%{ }^{\mathrm{A}}$ & $27.8 \% \%^{\mathrm{A}}$ & $34.4 \% \mathrm{~A}^{\mathrm{A}}$ & \\
\hline \multirow{2}{*}{ Code (E) } & n & 10 & 0 & 0 & \\
\hline & $\%$ & $3.9 \%^{\mathrm{B}}$ & $0 \%{ }^{\mathrm{A}}$ & $0 \%{ }^{\mathrm{A}}$ & \\
\hline \multirow{2}{*}{ Code $(F)$} & $\mathbf{n}$ & 76 & 144 & 41 & \\
\hline & $\%$ & $29.6 \% \mathrm{C}$ & $47.7 \%^{\mathrm{B}}$ & $18.1 \%^{\mathrm{A}}$ & \\
\hline \multirow{2}{*}{ Total } & $\mathbf{n}$ & 257 & 302 & 227 & \\
\hline & $\%$ & $100 \%$ & $100 \%$ & $100 \%$ & \\
\hline
\end{tabular}

Different superscript letters within the same row indicates a statistically significant difference

*; significant $(p \leq 0.05)$ ns; non-significant $(p>0.05)$

The highest percentage of Code (A) and (C) was found in group (I) followed by group (I) then group (III). The highest percentage of Code (B) was found in group (I) followed by group (III) then group (II). The highest percentage of Code (D) was found in group (III) followed by group (II) and then group (I). Code (E) was only found in group (I). The highest percentage of Code (F) was found in group (II) followed by group (I) then group (III). The majority of group (III) was code (D) while the majority of groups (II) and (I) was code (F). There was a significant difference between the three groups. Pairwise comparison for codes (A) and (C) showed a significant difference between groups (III) and (II). For code (B) there was a significant difference 
between groups (II) and (I). For code (E) there was a significant difference between group (I) and groups (III) and (II). For code (F) there was a significant difference between all the three groups. All other pairs showed no significant difference.

\section{3- Compariosn of the area of surface affected by the erosion in all groups:}

Frequencies (n), Percentages (\%), for the area of surface affected by the erosion in all groups in table (3) and figure (5)

TABLE (3): Frequencies (n), Percentages (\%) for the area of surface affected by the erosion in all groups

\begin{tabular}{|c|c|c|c|c|c|}
\hline \multicolumn{2}{|c|}{$\begin{array}{l}\text { Area of sur- } \\
\text { face affected } \\
\text { by the erosion }\end{array}$} & $\begin{array}{c}\text { Group } \\
\text { (I) }\end{array}$ & $\begin{array}{c}\text { Group } \\
\text { (II) }\end{array}$ & $\begin{array}{c}\text { Group } \\
\text { (III) }\end{array}$ & P-value \\
\hline \multirow{2}{*}{ Code (-) } & n & 217 & 84 & 208 & \multirow{6}{*}{$<0.001 *$} \\
\hline & $\%$ & $87.5 \%^{\mathrm{A}}$ & $27.8 \%^{\mathrm{B}}$ & $91.6 \%{ }^{\mathrm{A}}$ & \\
\hline \multirow{2}{*}{ Code (+) } & n & 31 & 218 & 19 & \\
\hline & $\%$ & $12.5 \%^{\mathrm{A}}$ & $72.2 \%^{\mathrm{B}}$ & $8.4 \%^{\mathrm{A}}$ & \\
\hline \multirow{2}{*}{ Total } & n & 248 & 302 & 227 & \\
\hline & $\%$ & $100 \%$ & $100 \%$ & $100 \%$ & \\
\hline
\end{tabular}

Different superscript letters within the same row indicates a statistically significant difference

*; significant ( $p \leq 0.05) n s ;$ non-significant $(p>0.05)$

The highest percentage of code (-) was found in group (III) followed by group (I) then group (II). The highest percentage of code (+) was found in group (II) followed by group (I) then group (III). The majority of groups (I) and (III) was code (-) while the majority of group (II) was cade (+). There was a significant difference between the three groups. Pairwise comparison for both codes there was no significant difference between groups (I) and (III) while group (II) was significantly different from both groups.

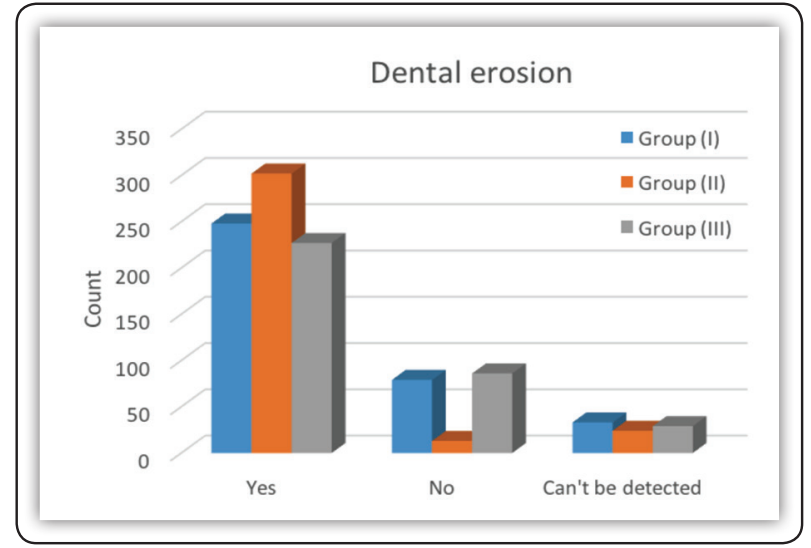

Fig. (3): Bar chart showing count of the prevalence of dental erosion in all groups

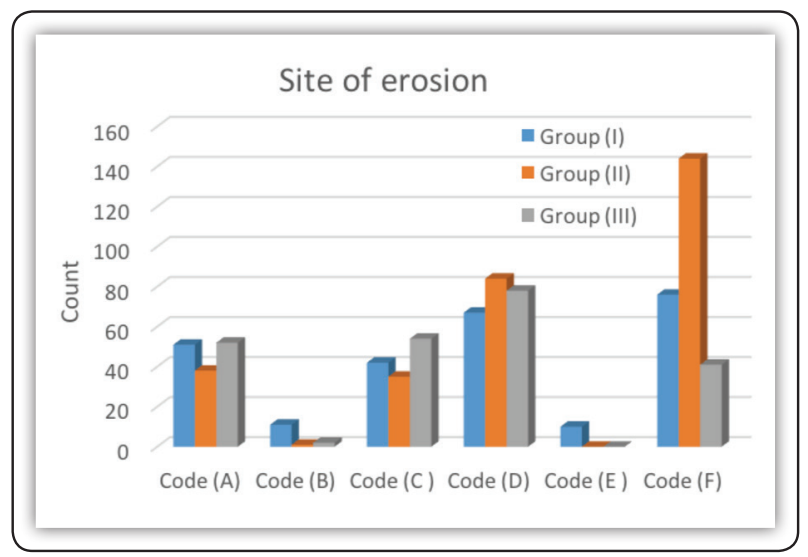

Fig. (4): Bar chart showing count of the site of dental erosion in all groups

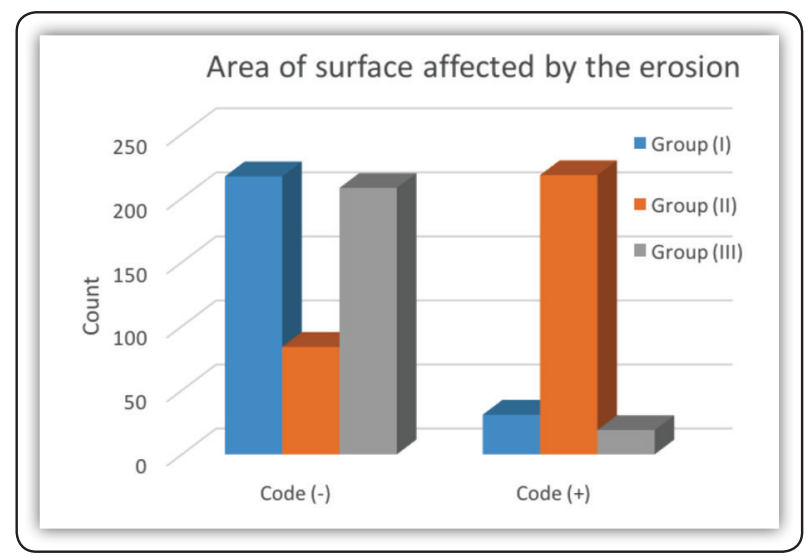

Fig. (5): Bar chart showing count of the area of surface affected by the erosion in all groups 


\section{DISCUSSION}

Dental erosion according to Pindborg is a superficial loss of dental hard tissue by a chemical process that does not involve bacteria ${ }^{(9)}$.

Dental erosion seems to be a problem for the dental profession in this millennium. It is still doubtful if this is due to a true increase in its prevalence or the dental profession has become more aware of the condition with better diagnostic means ${ }^{(10)}$.

The UK Child Dental Survey in 1993 found that there were over 50 per cent of five-year-old children with erosion in their primary incisors and 25 per cent of 12 to 14-year-old children had their permanent dentition affected. If this condition is not controlled and stabilized, the child may suffer from severe tooth surface loss, tooth sensitivity, over closure, poor aesthetics, or even dental abscesses in the affected teeth $^{(10)}$.

Children with heart disease requires special attention, because of their heightened susceptibility to infectious endocarditis, associated with bacteremia induced by invasive dental procedures. Furthermore, these patients commonly have developmental enamel defects that increase caries risk, and often have poor oral health. The latter condition may be largely attributed to cardiac disease, whose attention and care may cause oral health to be underestimated and not be given due importance. In addition, the chronic administration of medicines sweetened with sucrose and acidic drugs such as aspirin may increase the incidence of caries and gingivitis in children. Dental disease may lead to dental extractions in young children, possibly requiring general anesthesia $^{(11,12)}$.

Therefore, this in-vivo study aimed to assess the erosive effect of aspirin on primary teeth enamel in children with heart diseases and to determine the proper route of administration to control that erosive effect.
In vivo part, children with congenital heart diseases ${ }^{(4)}$ and with rheumatic heart disease were clinically checked intraoral, to measure erosion if present by using o'sullivan erosion index because it is designed for the measurement of erosion specifically in children. The index was qualitative with a broad attempt at quantification noting whether less or more than half of the surface was affected. Every tooth was examined and assigned a three-digit score relating to the site of erosion, severity (grade $0-5$ ) and area of surface affected ${ }^{(8)}$.

In this study children were divided into three groups according to their consumption of aspirin doses, first group was children with rheumatic heart disease who take aspirin for short duration but in large divided doses $75-100 \mathrm{mg} / \mathrm{kg} /$ day divided on 4 doses for 2- 6 weeks to treat inflammation ${ }^{(7)}$.

Second group was children with cyanotic CHD who take aspirin for long duration but in small doses, $5 \mathrm{mg} / \mathrm{kg} /$ day in single dose daily for life long to act as antiplatelet according to American Heart Association ${ }^{(7)}$.

Third group was children with acyanotic CHD who don't take aspirin due to lack of hypoxia and subsequently lack of erythrocytosis there is no need for aspirin or any substitute unlike cyanotic heart disease.

This study showed that children with RHD suffer from dental erosion and that was in agreement with the study that carried out in New Zealand and have shown that children with RHD suffer from teeth erosion more than normal children ${ }^{(2)}$.

This study showed that children with CCD suffer from sever dental erosion and that is consistent with a study done by Kerrod (1992) and showed that CCD children generally suffered poorer oral health, with primary dentitions, $52 \%$ o f CCD children had dental erosion compared with only $23 \%$ in the control group ${ }^{(13)}$. 
Additionally, this study proven that the highest percentage of dental erosion occurred in the second group who consume chronic doses of aspirin and that is in agreement with another clinical case study done by Maccracken showed that the occlusal surface of the lower premolars and molars in individual consume chronic doses of aspirin suffer from severe erosion ${ }^{(14)}$.

\section{REFERENCE}

1- Mccrindle W: Cardiovascular consequences of pediatric obesity: will there be a future epidemic of premature cardiovascular disease? Ped Child Health. 2007;12(3): 175-177.

2- Thornley, Sundog G: Rheumatic fever in New Zealand: what are the teeth trying to tell us? J of Dent. 2014; 20(1):7-10.

3- Bolan M, Ferreira M, Veira R: Erosive effects of acidic center-filled chewing gum on primary and permanent enamel. J of Ind Society Pedo Prev Dent. 2008; 970: 149-152.

4- Luana S, Carolina D, Nail D, Marisa M, Cristiano S: Dental erosion among 12-year-old school children: a population-based-cross-sectional study in South Brazil. J of Pub Health Dent. 2015; 65:322-330.

5- Abhinay C, Shweta C, Jay C, Aditi J, Puneet G, Priyanka $\mathrm{T}$ : Indices for measuring dental erosion. Chatti J of Health Sciences. 2013; 1:35-46.
6- Lussi A, Kohler N, Zero D, Schaner M, Mergret B: A comparison of the erosive potential of different beverages in primary and permanent teeth using an in vitro model. Eur J of Oral Science .2000;108:110-114.

7- Belay D, Bresee S, Holman C, Khan S: Reye's syndrome in the united states from 1981 through 1997. New Eng J of Med. 1999;340(18):1377-1382.

8- O'sullivan EA: A new index for the measurement of erosion in children. Eur J of Paed Dent. 2000; 1:69-74.

9- Al-Dlaigan YH, Shaw L, Smith AJ. Is there a relationship between asthma and dental erosion? A case control study. Int J Ped Dent 2002; 12:189-200.

10- O Brein M. Children's dental health in the United Kingdom 1993. OPCS, London: HMSO, 1994;34:232-240.

11- Elizangela P, Vitor A, Rodolfo C, Luciana R, Andrea L: Caries experience in young children with congenital heart disease in a developing country. $\mathrm{J}$ of Brazil Oral Res. 2013;27(2):103-108.

12- Silva B, Souza R, Cunha A: Knowledge, attitudes and status of oral health in children at risk for infective endocarditis. Int J of Ped Dent. 2002;12(2):124-131.

13- Kerrod B, Dorothy J, Radford W, Kim S: Oral health of children with congenital heart diseases: a controlled study. J of Ped Dent. 1992; 14:224-230.

14- Maccracken M, Neal S: Dental erosion and aspirin headache powder; clinical report. J of Prosthodontic. 2009; 9(2):95-98 